\title{
Reabilitação anterossuperior com técnica direta em resina composta
}

\begin{abstract}
- Carine Zanchin Departamento de Reabilitação Oral, Universidade Estadual do Oeste do Paraná, Cascavel, PR, Brasil • Leonardo de Almeida Departamento de Reabilitação Oral, Universidade Estadual do Oeste do Paraná, Cascavel, PR, Brasil • Eduardo Benassi dos Santos Departamento de Reabilitação Oral, Universidade Estadual do Oeste do Paraná, Cascavel, PR, Brasil • Guilherme Schmitt de Andrade Departamento de Prótese Dentária, Instituto de Ciência e Tecnologia, Universidade Estadual Paulista "Julio de Mesquita Filho", São José dos Campos, SP, Brasil - Fabiana Scarparo Naufel Departamento de Dentística, Universidade Estadual do Oeste do Paraná, Cascavel, PR, Brasil • Vera Lucia Schmitt Departamento de Dentística, Universidade Estadual do Oeste do Paraná, Cascavel, PR, Brasil
\end{abstract}

RESUMO || A odontologia sofre constantemente mudanças nos seus padrões de qualidade, porém, sempre devemos lançar mão, independente do procedimento restaurador, da famosa tríade: saúde, função e estética. Objetivo: Este relato de caso tem por finalidade demonstrar a técnica de facetas diretas em resina composta. Materiais e Métodos: Utilizou-se guia de silicone em resina composta de forma direta para reabilitar uma paciente com múltiplos diastemas anterossuperiores. Resultado: A utilização da guia em silicone facilitou a confecção da concha palatina por já ter formato, comprimento e largura preestabelecidos no enceramento diagnóstico. Paciente, jovem, demonstrou bastante entusiasmo após o término do procedimento. Conclusão: ainda na atualidade é possível não utilizar formas invasivas para reabilitações, principalmente nos casos de pacientes jovens.

DESCRITORES || Resinas Compostas; Restauração Dentária; Odontologia Operatória.

ABSTRACT | Anterosuperior rehabilitation with direct composite resin technique • Dentistry constantly undergoes changes in its quality standards, but we must always make use of them, regardless of the restorative procedure of the famous triad: health, function and aesthetics. Objective: this case report demonstrates the technique of direct veneers in composite resin. Materials and Methods: a silicone guide was used in composite resin directly to rehabilitate a patient with multiple anterosuperior diastemes. Result: The use of silicone guide facilitated the making of the palatine shell since it already has a pre-established shape, length and width in the diagnostic waxing. The patient was young and showed a lot of enthusiasm after the end of the procedure, thus satisfying the operator. Conclusion: it is still possible not to use invasive forms for rehabilitation, especially in the cases of young patients.

DESCRIPTORS | Composite Resins; Dental Restoration; Operative Dentistry. 


\section{INTRODUÇÃO}

A aparência afeta diretamente a autoestima do paciente, e, para melhorar a autoimagem e obter maior aceitação pela sociedade, existe atualmente uma crescente valorização da estética e uma grande demanda de pacientes por tratamentos odontológicos que tornem o sorriso esteticamente agradável. ${ }^{1-3}$

A assimetria, a falta de proporção entre os dentes e diastemas, e as alterações de cor e textura, sobretudo nos anteriores, causam uma desarmonia do sorriso, deixando a estética desagradável. Porém, só se faz necessária a correção do diastema quando parte do paciente, de forma espontânea, o desejo de realizá-la. ${ }^{1,4}$

Durante o planejamento estético e funcional, é importante se atentar às queixas, avaliar as perspectivas e expectativas do paciente, a condição financeira, a oclusão e o tempo disponível, para então oferecer o melhor tratamento para cada caso, e assim obter uma maior satisfação com o resultado. ${ }^{4,5}$

As resinas compostas atualmente oferecem uma gama de cores e de translucidez e podem ser indicadas para: corrigir alterações na anatomia, ângulos incisais, bossas, sulcos de desenvolvimento, fechamento de diastemas, além de problemas com alinhamento e posicionamento. Com a técnica de estratificação, pode ser obtida excelente estética, pois é possível mimetizar as propriedades ópticas dos dentes naturais. ${ }^{1,2,4}$

As principais vantagens da técnica direta frente às cerâmicas são: procedimentos minimamente invasivos, com máxima preservação dental, podendo ser reversíveis, facilmente reparados, além de causar menor desgaste dos dentes antagonistas, serem menos onerosos e requererem menor tempo de tratamento. Porém como desvantagens, as resinas apresentam menor resistência à compressão e fratura, e a estabilidade de cor não é tão boa quanto das cerâmicas, sendo necessários refazer as etapas de acabamento e polimento com certa frequência. ${ }^{2,4}$

É importante ressaltar que o conceito de estética é subjetivo e está relacionado com os fatores sociais, culturais e psicológicos do paciente, e por isso deve ser levada em conta também a expectativa do paciente, pois o que é cosmeticamente agradável ao cirurgião-dentista pode não ser para o paciente, e disto depende o sucesso na reabilitação.3,4,6

Sendo assim, este artigo tem por objetivo relatar um caso clínico de remodelação estética dental, através da confecção de facetas diretas em resina composta em dentes anteriores superiores de uma paciente jovem, a qual possuía diastemas e dentes com alterações de forma.

\section{RELATO DE CASO}

Paciente G.K., 24 anos, sexo feminino, procurou atendimento da Residência em Reabilitação Oral da Unioeste, relatando insatisfação com a estética dental dos elementos anteriores. Suas principais queixas consistiam nos diastemas, na forma e no tamanho dos elementos dentais, além da coloração dentária.

No exame clínico foi observado que a paciente possuía todos os elementos anteriores superiores hígidos, diastemas, incisivos centrais superiores desproporcionais, e caninos superiores conoides. Observa-se a condição inicial na Figura 1.

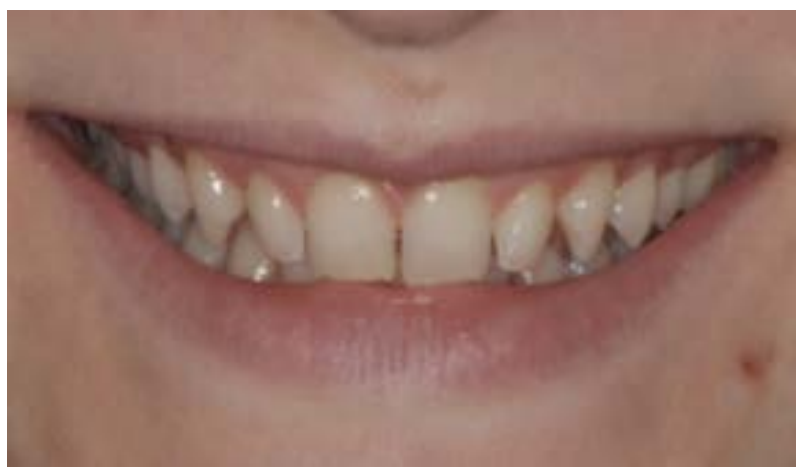

FIGURA 1 | Foto Inicial.

Foram realizadas fotografias e a moldagem inicial, para obtenção do modelo de estudo, e então foi traçado o plano de tratamento e realizado um enceramento diagnóstico, conforme a Figura 2. O enceramento foi transferido para a boca através de uma guia de silicone realizada sobre o modelo 
encerado da paciente, a qual foi preenchida por resina bisacrílica e posicionada sobre os dentes, técnica chamada de mock-up, usada como uma pré visualização do resultado final do tratamento, para avaliação de tamanho, forma e comprimento, e também para a aprovação pela paciente.

Após remover a guia de silicone, foi realizado um acabamento para remoção dos excessos de resina bisacrílica. O resultado da prova através do mock-up pode ser observado na Figura 3.

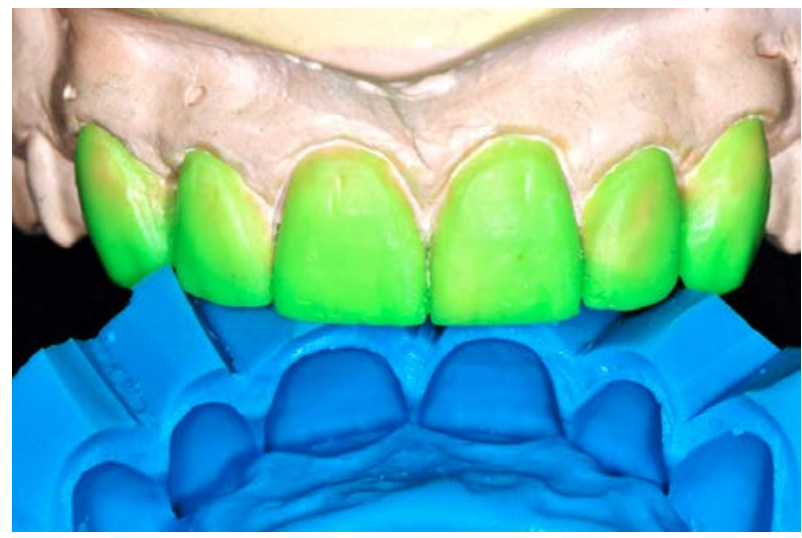

FIGURA 2 | Modelo Encerado e Guia em silicone para mock-up.

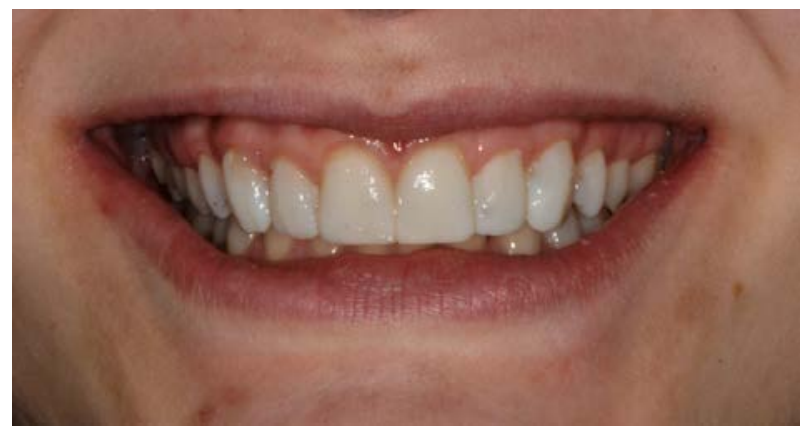

FIGURA 3 | Mock-up em Resina Bisacrilica.

Então foi proposto à paciente a realização de clareamento dental e reanatomização dentária, utilizando resina composta. Foram apresentadas à paciente as vantagens e desvantagens da técnica direta, e ela optou pelas restaurações diretas em resina composta.

Foi realizado o clareamento dos elementos dentais pela técnica supervisionada pelo dentista. A cor inicial tomada foi A2, conforme a
Figura 4A; após a primeira sessão de clareamento, os elementos chegaram à cor A1 (Figura 4B) e, após a segunda sessão de clareamento, chegou à cor B1 (Figura 4C).



FIGURA 4 | A) Seleção de cor prévia ao clareamento; B) Seleção de cor após a primeira sessão de clareamento; C) Cor final após a segunda sessão de clareamento.

Depois da aprovação do mock-up pela paciente e o aguardo de 21 dias após o clareamento, foi realizada a seleção de cor das resinas de esmalte e dentina, conforme a Figura 5.

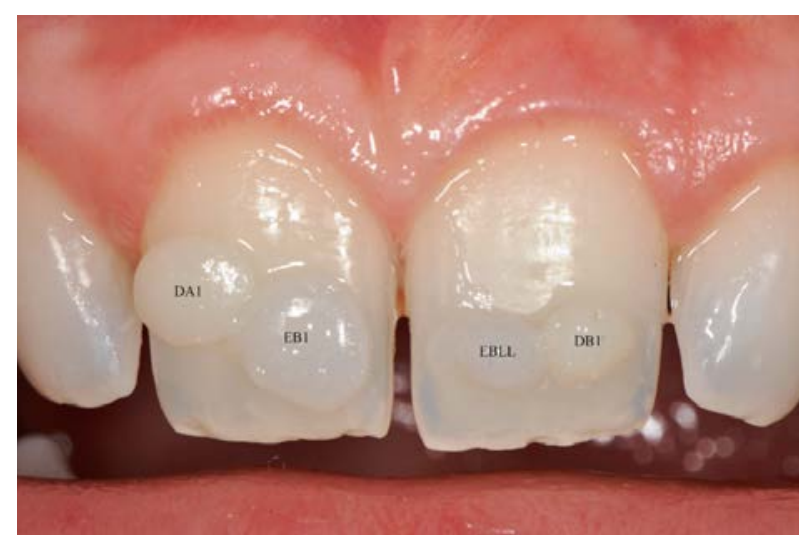

FIGURA 5 | Seleção de cor das resinas compostas.

Foi realizada profilaxia com pedra-pomes de todos os elementos dentais, seguida do isolamento do campo operatório o e uso de fio retrator de numeração ooo de canino direito superior ao canino esquerdo superior para afastamento gengival. Foi então aplicado o ácido fosfórico em esmalte por 30 segundos (Figura 6A) lavado 
em abundância com água por 30 segundos (Figuras 6B e 6C), aplicado adesivo Scotch Bond (3M Brasil, Sumaré, São Paulo, Brasil) convencional de 3 passos (Figura 6D) e, então, fotoativado. Com uma matriz de metal de $0,7 \mathrm{~mm}$, foi conferido se não houve união dos dentes no ponto de contato.



FIGURA 6 || A) Aplicação do ácido fosfórico; B) Remoção do ácido fosfórico com água; C) Após secagem dos elementos dentários; D) Após aplicação do sistema adesivo.

Foi utilizada a técnica de estratificação da resina nas restaurações, iniciando pela prova da guia palatina para conferência de adaptação nos elementos dentais (Figura 7A). A resina utilizada para a face palatina foi a de matiz BL-L, para recobrir o dente e criar a camada de dentina, foi utilizada a matiz B1, já a camada de esmalte foi confeccionada com a matiz BL-L. Foi iniciado o procedimento restaurador ao confeccionar a barreira palatina utilizando incrementos de uma resina composta nanohíbrida (IPS Empress Direct, Ivoclar VivadentSchann, Liechtenstein) de cor BL-L, que foram posicionados sobre a matriz de silicone, formando uma fina camada de resina. Então, foi levado em posição, adaptando na face palatina dos dentes anteriores, e feita a individualização ou separação dente a dente, com auxilio de uma espátula de resina composta. $\mathrm{Na}$ sequência, foi realizada a fotoativação por 20 segundos, removida a matriz e fotoativado mais 20 segundos pela face palatina de cada elemento dental, obtendo-se então a face palatina dos dentes anteriores (Figura 7B).

Para mimetizar a camada de dentina, foram utilizados incrementos de resina de dentina na cor A1 IPS Empress Direct, deixando livre as áreas de translucidez do esmalte e, para finalizar a restauração toda a face vestibular dos dentes, foi recoberta com a resina de esmalte cor B1 IPS Empress Direct, facilitando a acomodação das resinas. Espátulas de inserção e pincéis foram utilizados e, para a remoção de excessos proximais, foi utilizada uma matriz de poliéster. Com a finalidade de evitar a união dos elementos vizinhos, utilizou-se a fita para isolamento Isotape (TDV, Pomerode, Santa Catarina, Brasil) nas faces proximais de cada elemento dental. Os incrementos foram ativados por 20 segundos cada com o fotopolimerizador Valo Cordless (Ultradent, South Jordan, Utah, EUA). A condição final após o procedimento restaurador pode ser observada na Figura 8A.

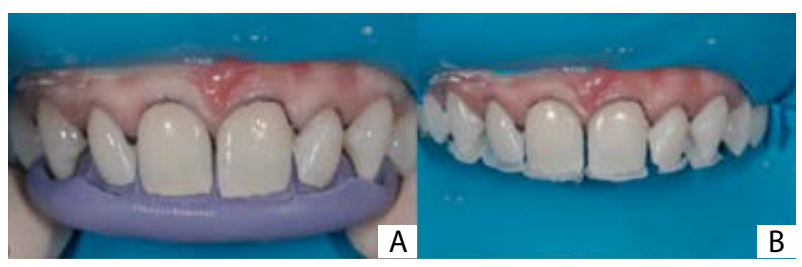

FIGURA 7 | A) Prova da guia palatina; B) Barreiras palatinas confeccionadas em resina composta.

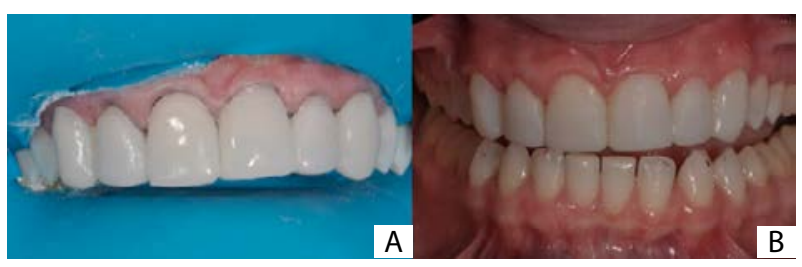

FIGURA 8 | A) Após finalizar o procedimento restaurador; B) Após remover o isolamento absoluto.

Após remover o isolamento e realizar os ajustes estéticos e funcionais (Figura 8B), foram utilizados discos abrasivos Sof-Lex Pop On (3M ESPE, St. Paul, Minnesota, EUA), seguindo a ordem decrescente de granulação e tiras de lixa de poliéster Epitex (GC America Inc., St. Alsip, Illinois, EUA) nas faces 
proximais dos dentes. Foi realizado o ajuste oclusal e checadas as guias de desoclusão da paciente: guia anterior e guia canino.

A Figura 9A mostra a condição inicial da paciente e a Figura 9B a condição após as facetas em resina composta.



FIGURA 9 || A) Caso clínico inicial; B) Caso clínico após a confecção das facetas em resina composta.

Após o período de expansão higroscópica da resina, foi realizado o acabamento das restaurações com brocas multilaminadas em forma de ponta de lápis em baixa rotação e discos de lixa em ordem decrescente de granulação. Na sequência, foi realizado o polimento das restaurações com borrachas abrasivas Enhance (Dentsply Sirona) de três diferentes granulações, da mais grossa para a mais fina, e depois foi utilizado um disco de feltro com pasta diamantada de polimento. Após o acabamento e polimento, os dentes ficaram com aspecto natural, satisfazendo as expectativas da paciente.

Após a reabilitação da paciente, foi confeccionado o aparelho miorrelaxante para a manutenção das restaurações em resina composta, pois a paciente relatou que havia iniciado apertamento, visto que passava por um período de grande estresse.

A paciente está em acompanhamento há um ano e a condição atual se encontra na Figura 10, na qual pode se observar que as restaurações estão em ótimo estado. Manteve-se a estabilidade de cor, brilho e textura e elas continuam esteticamente agradáveis, sendo este um fator de sucesso quando se trata de restaurações diretas em resina. A paciente foi orientada de que pode ser necessário novo acabamento e polimento e que é necessário continuar utilizando o aparelho miorrelaxante durante o sono, conforme Figura 11.

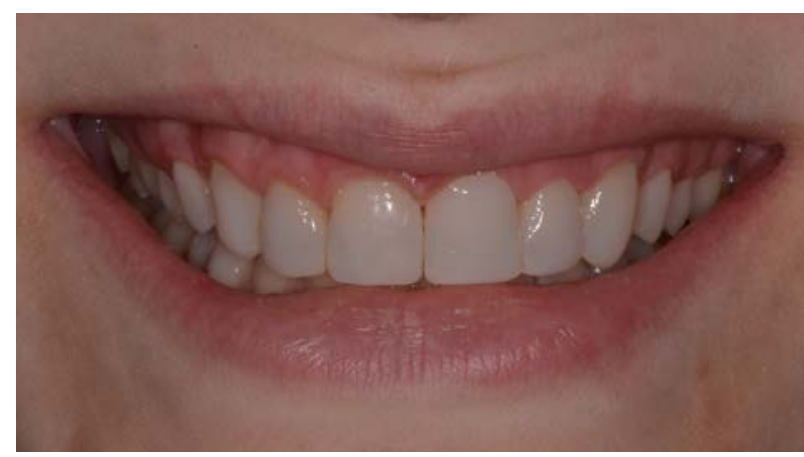

FIGURA 10 | Condição das facetas em resina composta após 1 ano de acompanhamento.

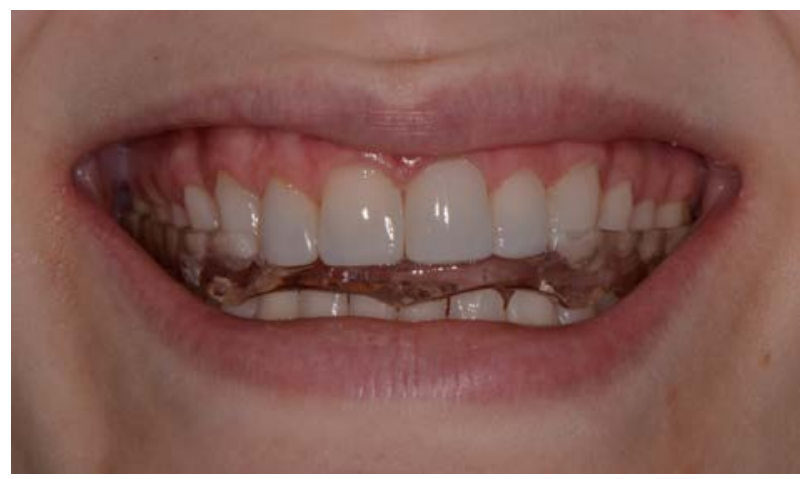

FIGURA 11 || Paciente utilizando o aparelho miorrelaxante.

\section{DISCUSSÃO}

As restaurações diretas nos elementos dentais anteriores tendem a ser mais complexas, uma vez que precisam mimetizar o elemento dental. É necessário que haja um domínio, pelo profissional, das diversas marcas comerciais de resinas compostas disponíveis no mercado, já que há variações no matiz, croma, valor, opacidade e translucidez, que permitem correção das imperfeições durante o procedimento restaurador.7

Existem inúmeras vantagens no uso da técnica da guia palatina: o tempo clínico reduzido, a facilidade de se inserir a resina, a possibilidade de a guia palatina prever a forma e tamanho dos dentes mais rapidamente, além de possibilitar a estratificação com diversas cores de resina composta. ${ }^{4,7}$

É indispensável realizar um correto diagnóstico e apresentar ao paciente todas as alternativas de 
tratamentos, explicando os riscos e benefícios, e entender quais são as expectativas do paciente, pois só assim resultados de sucesso e a satisfação do paciente poderão ser alcançados.3,4,8

Os diastemas são considerados antiestéticos e promovem uma percepção de desarmonia dental aos pacientes e à sociedade. A presença de espaçamento anterossuperior influencia negativamente a autopercepção da aparência. As etiologias podem ter vários fatores, como genética, ausência ou alterações no tamanho dental, posição ou angulação, overjet aumentado, freio lingual com baixa inserção, dentes supranumerários ou mesmo problemas periodontais. É importante avaliar o tamanho do diastema, para então definir se o melhor tratamento seria ortodôntico ou por meio de restauração direta ou indireta, equilibrando os padrões da proporção áurea e com perfil de emergência adequado, periodonto saudável e proporções dentais e interdentais satisfatórias. ${ }^{3,4,8,9}$

Em casos de fechamento de diastema, é importante fazer o enceramento diagnóstico sobre o modelo de gesso para ser realizado o ensaio restaurador ou mock-up, pois este possibilita ao profissional e ao paciente ter uma prévia do procedimento restaurador e assim poder avaliar as dimensões dentais e a aprovação do planejamento. Além disso, a realização do mock-up também ajuda na seleção de cor, além de permitir confeccionar sobre o modelo encerado uma guia de silicone. Com o enceramento e ensaio restaurador, é mais provável que o paciente fique satisfeito com o resultado, pois ele já vai ter visto uma prévia do tratamento e o terá aprovado. ${ }^{3,9}$

Após o procedimento restaurador, é imprescindível o ajuste oclusal. Deve ser avaliado os contatos dentais em máxima intercuspidação habitual e nos movimentos excursivos da mandíbula, como lateralidade e protusão, e removidos os contatos prematuros. ${ }^{3,9}$
No caso clínico em questão, foi optada pela técnica de facetas diretas em resina composta, pois esta permite que sejam realizadas remodelações cosméticas, corrigindo alterações de forma, posição e coloração de forma rápida e eficiente. Além disso, ela permite que seja reparado posteriormente caso seja necessário, além de preservar o tecido dentário e possuir o atrativo econômico. Quando confeccionadas sobre esmalte, têm uma forte aderência, que é maior quando realizado o condicionamento ácido total do esmalte, se comparada aos autocondicionantes. O condicionamento acido prévio causa uma desmineralização, formando microporosidades que servirão de microrretenções. ${ }^{8}$

Já quanto as restaurações indiretas, estas possuem algumas desvantagens, pois necessitam um desgaste dental mais extenso e possuem um maior custo. ${ }^{8}$ Nas restaurações estéticas, é preciso utilizar resinas que mimetizarão as cores e as formas dos elementos dentais naturais. As resinas indicadas para as facetas diretas devem possuir excelente lisura superficial com elevado brilho de superfície após polimento, alto conteúdo de carga que forneça alta resistência a compressão, fratura e desgaste, além de cores estáveis. ${ }^{8}$

A matriz palatina, ou muralha de silicone, consiste em uma técnica que realiza a moldagem prévia com silicone de condensação dos dentes que possuem alteração de cor e formato, com o objetivo de reproduzir a face palatina dos dentes anteriores com contatos e guias oclusais satisfatórias, o que simplifica o ajuste estético e funcional. Essa técnica possui vantagens tanto na questão anatômica quanto funcional, além de facilitar a inserção da resina no dente. Por isso, ela foi utilizada neste caso clínico; no entanto, a moldagem prévia foi realizada sobre o modelo encerado. ${ }^{4,8}$

É fundamental analisar o tamanho do diastema para definir o melhor tratamento, que promova harmonia entre a largura e o comprimento do dente, visando, 
assim, o equilíbrio no procedimento restaurador de acordo com os padrões da proporção áurea. ${ }^{8}$

Apesar da técnica direta possuir limitações, como o aparecimento de microtrincas, pequenas fraturas e lascas, sobretudo quando associadas a críticas cargas oclusais, ainda é possível realizar transformações estéticas com resinas compostas e obter sucesso, sendo uma alternativa simples e eficaz com previsibilidade e prognóstico favorável quando bem indicada. ${ }^{1,3,4}$

\section{CONCLUSÃO}

O procedimento realizado transformou o sorriso da paciente, elevando sua autoestima, além de ser minimamente invasivo, compatível com a idade da paciente e realizado rapidamente em apenas uma sessão clínica.

\section{REFERÊNCIAS}

1. Goyatá FR, Costa HV, Marques LHG, Barreiros ID, Lanza CRM, Novaes JB Jr, et al. Remodelação estética do sorriso com resina composta e clareamento dental em paciente jovem: relato de caso. Arch Health Invest. 2017;6(9):408-13. doi: 10.21270/archi.v6i9.2224

2. Gouveia CG, Moreira Junior R, Peralta FS, Scherma AP, Resende LFM. Facetas diretas de resina composta em dentes anteriores: relato de caso. Clin Pesq Odontol Unitau. 2018;9(1):44-50.

3. Schwarz V, Simon LS, Silva AS, Ghiggi PC, Cericato GO. Fechamento de diastema com resina composta; relato de caso. J Oral Invest. 2013;2(1):26-31.

4. Braga AT, Monteiro DDH, Munari LS, Cornacchia TPM. Acompanhamento de restaurações em resina composta pela técnica da barreira palatina: relato de caso. Rev Odontol Bras Central. 2016;25(74):112-7.

5. Reis GR, Olivera LTM, Vilela ALR, Menezes MS. Mock-up: previsibilidade e facilitador das restaurações estéticas em resina composta. Rev Odontol Bras Central. 2018; 27 (81):105-11.

6. Pereira DA, Borges MG, Silva FP, Menezes MS. Reabilitação estética do sorriso por meio de procedimento restaurador direto com resina composta nanoparticulada: relato de caso. Rev Odontol Bras Central. 2016;25(72):54-8.

7. Vettori SS, Miranda F, Gatelli LJ, Costa MMTM, Amaral RC, Dallanora FJ, et al. Restauração estratificada em resina composta com o uso de guia palatina em dentes anteriores. Ação Odonto. 2018;(1):103-9.

8. Berwanger C, Rodrigues RB, Ev LD, Denadai GA, Erhardt MCG, Coelho-de-Souza FH. Fechamento de diastema com resina composta direta - relato de caso clínico. Rev Assoc Paul Cir Dent. 2016;70(3);317-22.

9. Guerra MLRS, Venâncio GN, Augusto CR. Fechamento de diastemas anteriores com resina composta direta: relato de caso. Rev Fac Odontol Lins. 2017;27(1):63-8. doi: 10.1560o/22381236/fol.v27n1p63-68 